\title{
EFEITO DE SEMEADORA COM HASTE SULCADORA PARA AÇÃO PROFUNDA EM SOLO MANEJADO COM PLANTIO DIRETO $^{(1)}$
}

\author{
Márcio Renato Nunes ${ }^{(2)}$, José Eloir Denardin ${ }^{(3)}$, Antonio Faganello(3), Eloy Antonio \\ Pauletto $^{(4)}$ \& Luiz Fernando Spinelli Pinto ${ }^{(4)}$
}

\begin{abstract}
RESUMO
A adoção do plantio direto na região subtropical úmida do Brasil, fundamentada apenas em dois preceitos da agricultura conservacionista - mobilização de solo restrita à linha de semeadura e manutenção de resíduos culturais na superfície do solo -, tem induzido à estratificação de atributos químicos do solo na camada de 0$20 \mathrm{~cm}$ profundidade e degradação física da camada subsuperficial (entre aproximadamente $5-20 \mathrm{~cm}$ de profundidade), que podem contribuir para frustrações de safras agrícolas, quando da ocorrência de estiagens. $O$ objetivo deste trabalho foi avaliar o efeito residual de uma semeadora/adubadora, equipada com elemento rompedor de solo tipo haste sulcadora, atuando em quatro profundidades para a semeadura de milho (Zea mays L.), na mitigação de problemas de ordem física e química, em um Latossolo Vermelho distrófico húmico, manejado em plantio direto há mais de 10 anos. Os tratamentos avaliados foram: $T_{1}=$ hastes sulcadoras atuando até $5 \mathrm{~cm}$ de profundidade; $T_{2}=$ hastes sulcadoras atuando até $10 \mathrm{~cm}$ de profundidade; $T_{3}=$ hastes sulcadoras atuando até $15 \mathrm{~cm}$ de profundidade; $\mathrm{e} \mathrm{T}_{4}=$ hastes sulcadoras atuando até $17 \mathrm{~cm}$ de profundidade. $O$ efeito desses tratamentos sobre os atributos físicos do solo foi avaliado pela técnica do perfil cultural associada à determinação da densidade, porosidade total, macroporosidade e resistência do solo à penetração, aos oito e 12 meses, após a semeadura da cultura de milho. Sobre os atributos químicos, esses efeitos foram avaliados pela determinação de $\mathrm{pH} \mathrm{em}$ $\mathrm{H}_{2} \mathrm{O}, \mathrm{P}$ e K disponíveis, $\mathrm{Ca}, \mathrm{Mg}$ e $\mathrm{Al}$ trocáveis, acidez potencial e matéria orgânica, em amostras de solo coletadas em camadas de $2,5 \mathrm{~cm}$ de espessura, de 0-22,5 cm de profundidade. A utilização da semeadora/adubadora, equipada com elemento
\end{abstract}

(1) Recebido para publicação em 11 de junho de 2013 e aprovado em 10 de janeiro de 2014.

(2) Mestrando do Programa de Pós-Graduação em Manejo e Conservação do Solo e da Água, Faculdade de Agronomia "Eliseu Maciel", Universidade Federal de Pelotas - FAEM/UFPel. CEP 96010-900 Pelotas (RS). Bolsista da CAPES. E-mail: márcio_r_nunes@yahoo.com.br

(3) Pesquisador, Embrapa-Trigo. Rodovia BR 285, km 294. Caixa Postal 451. CEP 99001-970 Passo Fundo (RS). E-mail: denardin@cnpt.embrapa.br, afaganel@cnpt.embrapa.br

(4) Professor do Departamento de Solos, FAEM/UFPel. E-mail: pauletto_sul@yahoo.com.br, lfspin@ufpel.edu.br 
rompedor de solo tipo haste sulcadora, evidenciou-se eficaz em mitigar os problemas físicos e químicos do solo, tanto aos oito como aos 12 meses após a operação de semeadura.

Termos de indexação: camada compactada, manejo do solo, perfil cultural, estratificação química.

\title{
SUMMARY: EFFECT OF SEED DRILL WITH FIXED SHANKS FOR DEEP ACTION IN SOIL UNDER NO-TILL
}

\begin{abstract}
The adoption of no-till in the humid subtropical region of Brazil based on only two precepts of conservation agriculture, soil disturbance restricted to the crop row and crop residue maintained as soil cover, has led to stratification of soil chemical properties in the $0-20 \mathrm{~cm}$ soil layer and physical degradation of the subsurface layer (from approximately the $5-20 \mathrm{~cm}$ depth), which may make for lower yields during short term droughts. The aim of this study was to evaluate the residual effect of a seed drill/fertilizer applicator equipped with fixed shanks, set at four different depths, for the sowing of maize (Zea mays L.), in mitigation of chemical and physical problems in a Latossolo Vermelho distrófico húmico (Rhodic Hapludox) under no-till for more than ten years. The treatments were: $T_{1}=$ shank extremity at $5 \mathrm{~cm}$ depth; $T_{2}=$ shank extremity at $10 \mathrm{~cm}$ depth; $T_{3}=$ shank extremity at $15 \mathrm{~cm}$ depth; and $T_{4}=$ shank extremity at $17 \mathrm{~cm}$ depth. The crop profile method was used to evaluate soil physical properties (bulk density, total porosity, macroporosity, and soil resistance to penetration) at eight and ten months after sowing the maize. The chemical properties ( $\mathrm{pH}$ in water; available $P$ and $K$; exchangeable $\mathrm{Ca}, \mathrm{Mg}$, and $\mathrm{Al}$; potential acidity; and organic matter) were evaluated in layers every $2.5 \mathrm{~cm}$ from the $0-22.5 \mathrm{~cm}$ depth. The seed drill/fertilizer applicator equipped with fixed shanks for ripping the soil was able to mitigate soil physical and chemical problems, both at eight and 12 months after sowing.
\end{abstract}

Index terms: compacted layer, soil management, crop profile, chemical stratification.

\section{INTRODUÇÃO}

A expressão "sistema plantio direto" surgiu em meados dos anos 1980, em decorrência da percepção de que a viabilização do "plantio direto", de modo contínuo e ininterrupto, na região subtropical úmida do Brasil, requeria um conjunto de preceitos da agricultura conservacionista mais amplo do que simplesmente a mobilização de solo restrita à linha de semeadura e a consequente manutenção de resíduos culturais na superfície do solo.

O "plantio direto" necessitava ser entendido e praticado como "sistema de manejo" e não como mera forma alternativa de preparo de solo (Denardin et al., 2008; 2011). Assim, "sistema plantio direto" passou a ser consensualmente conceituado como um complexo de preceitos da agricultura conservacionista destinado à exploração de sistemas agrícolas produtivos, compreendendo: mobilização de solo exclusivamente na linha ou cova de semeadura ou de plantio; manutenção de resíduos culturais na superfície do solo; diversificação de espécies via rotação, sucessão e, ou, consorciação de culturas; redução ou supressão do intervalo de tempo entre a colheita e a semeadura subsequente; manutenção da cobertura permanente de solo; e aporte de material orgânico ao solo em quantidade, qualidade e frequência compatíveis com a demanda biológica do solo.
Contudo, Denardin et al. (2008) relataram que, na região subtropical úmida do Brasil, 25 anos após essa nova percepção, ainda predominava a adoção do "plantio direto" em detrimento ao "sistema plantio direto". Em razão disso, observa-se estratificação de atributos químicos na camada de 0-20 cm de profundidade do solo (Selles et al., 1997; Costa et al., 2009; Nunes et al., 2011) e degradação física da camada subsuperficial, entre, aproximadamente, $5-20 \mathrm{~cm}$ de profundidade (Tormena et al., 1998; Richart et al., 2005; Reichert et al., 2007; Veiga et al., 2008; Drescher et al., 2011), que podem estar contribuindo para frustrações de safras agrícolas, quando da ocorrência de estiagens.

Na adoção do "plantio direto", em razão da ausência de diversificação de espécies cultivadas e do insuficiente aporte de material orgânico ao solo, a pressão exercida pelas máquinas, pelos equipamentos agrícolas (Tormena et al., 1998; Hamza \& Anderson, 2005; Veiga et al., 2007; Silveira et al., 2008) e, ou, o pisoteio animal (Lanzanova et al., 2007) sobre o solo promove o rearranjo dos agregados na matriz do solo e a expulsão de ar, reduzindo a porosidade total e elevando a densidade e a resistência do solo à penetração, caracterizando um processo de compactação de solo (Dias Jr. \& Pierce, 1996).

O processo de compactação desenvolve a camada subsuperficial que limita os fluxos descendente e 
ascendente de água e restringe o sistema radicular das plantas à camada superficial (De Maria et al., 1999; Beutler \& Centurion, 2004), concentrando-o, em média, até a profundidade de $5 \mathrm{~cm}$. A pronunciada concentração de nutrientes na camada superficial do solo (Selles et al., 1997; Spera et al., 2011; Nunes et al., 2011; Costa et al., 2009) também pode ser avaliada como fator da restrição de raízes até essa profundidade.

A deposição de fertilizantes na camada superficial de solos manejados sob "plantio direto" é resultante do emprego de semeadoras/adubadoras equipadas com elementos rompedores de solo tipo disco e, ou, haste sulcadora de ação rasa, limitada a $10 \mathrm{~cm}$ de profundidade (Denardin et al., 2008), sem contribuição para o pleno rompimento da camada compactada e aprofundamento do sistema radicular das plantas.

Sob "plantio direto", a camada subsuperficial compactada tem sido caracterizada por reduzida porosidade de aeração e elevada densidade do solo e resistência à penetração (Tormena et al., 1998, 2004; Stone \& Silveira, 2001; Beutler \& Centurion, 2001; Richart et al., 2005; Silveira et al., 2008; Drescher et al., 2011), podendo ser restritiva ao aprofundamento do sistema radicular das plantas. Em decorrência, as raízes concentram-se, principalmente, na camada superficial (De Maria et al., 1999; Beutler \& Centurion, 2004; Bergamin et al., 2010), onde, mesmo em curtos períodos sem chuva, se manifesta o déficit hídrico, em razão da baixa permeabilidade do solo (Silva et al., 2009), que limita a ascensão de água do subsolo para a superfície. Em consequência, a produtividade das culturas pode diminuir (Beutler \& Centurion, 2004; Freddi et al., 2007; Secco et al., 2009; Chen \& Weil, 2011).

A escarificação mecânica do solo é apontada como alternativa para mitigar a compactação do solo, por elevar a porosidade e reduzir a densidade do solo (Klein et al., 2008). Vieira \& Klein (2007) quantificaram elevação das taxas de condutividade hidráulica e de infiltração de água no solo em área manejada sob "plantio direto", mediante a aplicação da prática de escarificação mecânica. Porém, o efeito dessa prática, em solo sob "plantio direto", tem sido avaliado como efêmero, persistindo por aproximadamente um ano (Nicoloso et al., 2008; Girardello et al., 2011; Silva et al., 2012), além de contrapor aos preceitos do "plantio direto", aumentar o tráfego de máquinas e equipamentos na lavoura e elevar o custo de produção.

Do exposto, formularam-se as hipóteses de que: o emprego de semeadora/adubadora equipada com elemento rompedor de solo tipo haste sulcadora de ação profunda, $17 \mathrm{~cm}$, mitiga problemas de compactação do solo em sistema "plantio direto"; e a haste sulcadora de ação profunda $(17 \mathrm{~cm})$, ao romper a camada compactada na linha de semeadura, posiciona os fertilizantes em maior profundidade, amenizando o grau de estratificação química dos atributos do solo na camada de $0-20 \mathrm{~cm}$ de profundidade.
Assim, o objetivo deste trabalho foi avaliar o efeito residual de uma semeadora/adubadora, equipada com elemento rompedor de solo tipo haste sulcadora, atuando em quatro profundidades, para a semeadura de milho (Zea mays L.), na mitigação de problemas de ordem física e química, em um Latossolo Vermelho distrófico húmico, manejado em plantio direto há mais de 10 anos.

\section{MATERIAL E MÉTODOS}

O experimento foi conduzido no campo experimental da Empresa Brasileira de Pesquisa Agropecuária, Unidade Descentralizada Embrapa Trigo, localizado no município de Coxilha, RS, na latitude $28^{\circ} 11^{\prime} 20^{\prime \prime} \mathrm{S}$, longitude $52^{\circ} 19^{\prime} 62^{\prime \prime} \mathrm{W}$ e altitude de $691 \mathrm{~m}$, em um Latossolo Vermelho distrófico húmico (Streck et al., 2008). Conforme classificação de Köppen, o clima da região é Cfa, subtropical úmido.

A área experimental vinha sendo manejada, há pelo menos 10 anos sob "plantio direto", com o cultivo de soja (Glycine $\max$ (L.) Merrill) na safra de verão e de aveia-preta (Avena strigosa L.), na de inverno. Previamente, a aplicação dos tratamentos, na primeira semana de dezembro de 2010, o solo foi amostrado nas camadas de 0-10 e 10-20 cm de profundidade, para a caracterização da fertilidade química do solo (Quadro 1), e nas camadas de 0-5, 5-10, 10-15 e 15-20 cm, para a determinação dos teores de argila, que foram de 437, 533,555 e $545 \mathrm{~g} \mathrm{~kg}^{-1}$, respectivamente.

Na mesma data, para a caracterização do perfil cultural do solo (Tavares Filho, et al., 1999), antes da aplicação dos tratamentos, foram abertas trincheiras medindo $30 \mathrm{~cm}$ de profundidade, $60 \mathrm{~cm}$ de lado e 60 $\mathrm{cm}$ de comprimento. Nesse foram identificadas três camadas distintas: camada L, caracterizada por volume de solo solto e agregados de tamanhos variados, bem como porosidade visível a olho nu e presença de elevada quantidade de raízes; camada $\mathrm{C} \Delta$, caracterizada por volume de solo formando estrutura maciça e homogênea e agregados compactos, sem porosidade visível a olho nu e com menor concentração de raízes em relação à camada $L$; e camada $\mu$, caracterizada pela aparência de solo com estrutura na forma de grânulos e blocos, típica de um Latossolo Vermelho, sem presença de raízes (Figura 1). A análise do solo demonstrou que a camada de 5-20 cm de profundidade se apresentava compactada, indicando a pertinência do estudo proposto.

Em 10/12/2010, foi semeado o milho (Pioneer $32 \mathrm{R} 48 \mathrm{H}$ ), de ciclo superprecoce, em linhas espaçadas de $60 \mathrm{~cm}$, com 4,5 sementes viáveis por metro linear (75000 plantas ha-1). A semeadora/adubadora utilizada foi equipada com: disco liso, para cortar os resíduos de cultura; haste sulcadora, com $12 \mathrm{~mm}$ de espessura, ajustável para operar até $17 \mathrm{~cm}$ de profundidade, para abrir o sulco de semeadura e posicionar o fertilizante 
Quadro 1. Atributos químicos de um Latossolo Vermelho distrófico húmico nas camadas de 0-10 e 10-20 cm de profundidade, antes da instalação do ensaio

\begin{tabular}{|c|c|c|c|c|c|c|c|c|c|c|c|}
\hline Camada & $\mathrm{pH}\left(\mathrm{H}_{2} \mathrm{O}\right)$ & $\mathbf{P}$ & $\mathbf{K}$ & MO & $\mathrm{Al}^{3+}$ & $\mathrm{Ca}^{2+}$ & $\mathrm{Mg}^{2+}$ & $\mathrm{H}+\mathrm{Al}$ & CTC & SB & V \\
\hline $\mathrm{cm}$ & & $-\mathrm{m}$ & $\mathrm{n}^{-3}$ & $\mathrm{~g} \mathrm{dm}^{-3}$ & 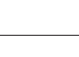 & 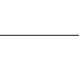 & $-\mathrm{cm}$ & $m^{-3}$ & & & $\%$ \\
\hline $0-10$ & 5,2 & 61,9 & 234,5 & 33,8 & 1,23 & 3,82 & 1,31 & 8,77 & 14,51 & 5,73 & 39,7 \\
\hline $10-20$ & 5,4 & 11,1 & 185,8 & 25,3 & 0,81 & 3,11 & 1,54 & 6,36 & 12,41 & 6,04 & 48,8 \\
\hline
\end{tabular}

CTC: Capacidade de troca de cátions potencial; e SB: Soma de bases.

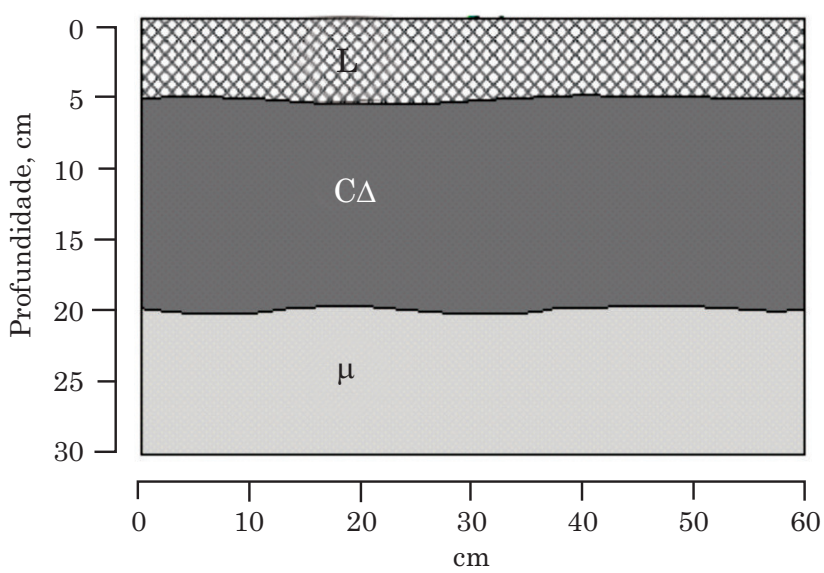

Figura 1. Perfil cultural do Latossolo Vermelho distrófico húmico, antes da instalação do ensaio: L é a camada de solo solto com macro e microagregados, porosidade visível a olho nu e abundante presença de raízes; $\mathrm{C} \Delta$, a camada de solo com estrutura maciça e homogênea, sem porosidade visível a olho nu e menor presença de raízes em relação à camada $L$; e $\mu$, a camada de solo com estrutura na forma de grânulos e de blocos, típica de Latossolo Vermelho.

no solo; discos duplos defasados, para posicionar a semente no solo; e um conjunto de duas rodas, de ação em forma de "V", para fechar o sulco de semeadura.

O delineamento experimental utilizado foi de blocos ao acaso com quatro repetições, em unidades experimentais com $9 \times 3,6 \mathrm{~m}\left(35,1 \mathrm{~m}^{2}\right)$. Os tratamentos foram constituídos por ajustes da haste sulcadora da semeadora, para atuar em quatro profundidades: $\mathrm{T}_{1}=$ até $5 \mathrm{~cm}$ de profundidade; $\mathrm{T}_{2}=$ até $10 \mathrm{~cm}$ de profundidade; $\mathrm{T}_{3}=$ até $15 \mathrm{~cm}$ de profundidade; e $\mathrm{T}_{4}=$ até $17 \mathrm{~cm}$ de profundidade. $\mathrm{O}$ tratamento $T_{1}$, haste sulcadora com ação até $5 \mathrm{~cm}$ de profundidade, foi considerado como tratamento testemunha, pois atuou na profundidade de trabalho correspondente a dos elementos rompedores de solo tipicamente adotados pelos produtores rurais da região de clima subtropical úmido do Brasil.

A adubação de base, realizada no ato da semeadura, foi de $280 \mathrm{~kg} \mathrm{ha}^{-1}$ da fórmula NPK 6-24-18. Aos $32 \mathrm{~d}$ após a semeadura, foi aplicado a lanço, na superfície do solo, $112 \mathrm{~kg} \mathrm{ha}^{-1}$ de $\mathrm{N}$, tendo como fonte ureia. A área não recebe calagem há pelo menos 10 anos. A colheita foi realizada em abril de 2011, sendo empregada colhedora automotriz para parcelas, marca Wintersteiger. Os restos culturais foram mantidos na superfície do solo, e a área foi mantida sem cultivo até dezembro de 2011.

Trincheiras para a descrição do perfil cultural (Tavares Filho et al., 1999) foram novamente abertas aos oito e 12 meses após a semeadura do milho, em cada unidade experimental. Essas foram posicionadas sobre as linhas onde a cultura de milho havia sido cultivada, mantendo-se a linha de cultivo no centro das trincheiras (Figura 2). No centro de cada camada de estrutura homogênea, na linha de semeadura do milho (Figura 2), o solo foi amostrado com estrutura preservada, em cilindros medindo 2,5 de altura $\times 5,6$ $\mathrm{cm}$ de diâmetro $\left(61,58 \mathrm{~cm}^{3}\right)$, para a determinação da densidade (Ds), porosidade total (Pt) e macroporosidade do solo (Ma), empregando-se métodos descritos em Embrapa (1997), e da resistência do solo à penetração (RP), com o emprego do penetrômetro marca Soiltest Inc., modelo CL-700, de escala zero a $500 \mathrm{kPa}$, dotado de ponteira plana com $6 \mathrm{~mm}$ de diâmetro. A resistência do solo à penetração foi realizada nas amostras com umidade equilibrada na mesa de tensão a - $6 \mathrm{kPa}$.

Aos oito meses após a aplicação dos tratamentos, nas mesmas trincheiras, o solo foi amostrado, com estrutura deformada, nas camadas de $0-2,5 ; 2,5-5,0$; $5,0-7,5 ; 7,5-10 ; 10,0-12,5 ; 12,5-15,0 ; 15,0-17,5 ; 17,5-$ 20,0; e 20,0-22,5 cm de profundidade, para a determinação dos seguintes atributos: $\mathrm{pH}$ em água, concentração de $\mathrm{P}$ e K (Mehlich-1), $\mathrm{Ca}, \mathrm{Mg}$ e Al trocáveis, acidez potencial $(\mathrm{H}+\mathrm{Al})$ e teor de matéria orgânica, conforme Embrapa (1997).

Os dados gerados em cada época de amostragem foram submetidos à análise da variância. Quando observado efeito significativo dos fatores avaliados, procedeu-se à comparação entre as médias pelo teste Tukey a $5 \%$. A persistência do efeito proporcionado pela haste sulcadora de ação profunda $(17 \mathrm{~cm})$ no solo foi avaliada pelo método de análise de medidas repetidas a partir de um modelo linear misto com a adoção da matriz de covariância não estruturada. Quando observados efeitos significativos na interação tratamento vs tempo, efetuou-se a comparação por contrastes ortogonais para as médias das épocas de amostragem (oito vs 12 meses) apenas para o tratamento $\mathrm{T}_{4}$ do fator profundidade de ação da haste sulcadora $(17 \mathrm{~cm})$. Os procedimentos de análise foram realizados com auxílio do software estatístico SAS $^{\circledR}$ versão 2009 (SAS, 2009). 

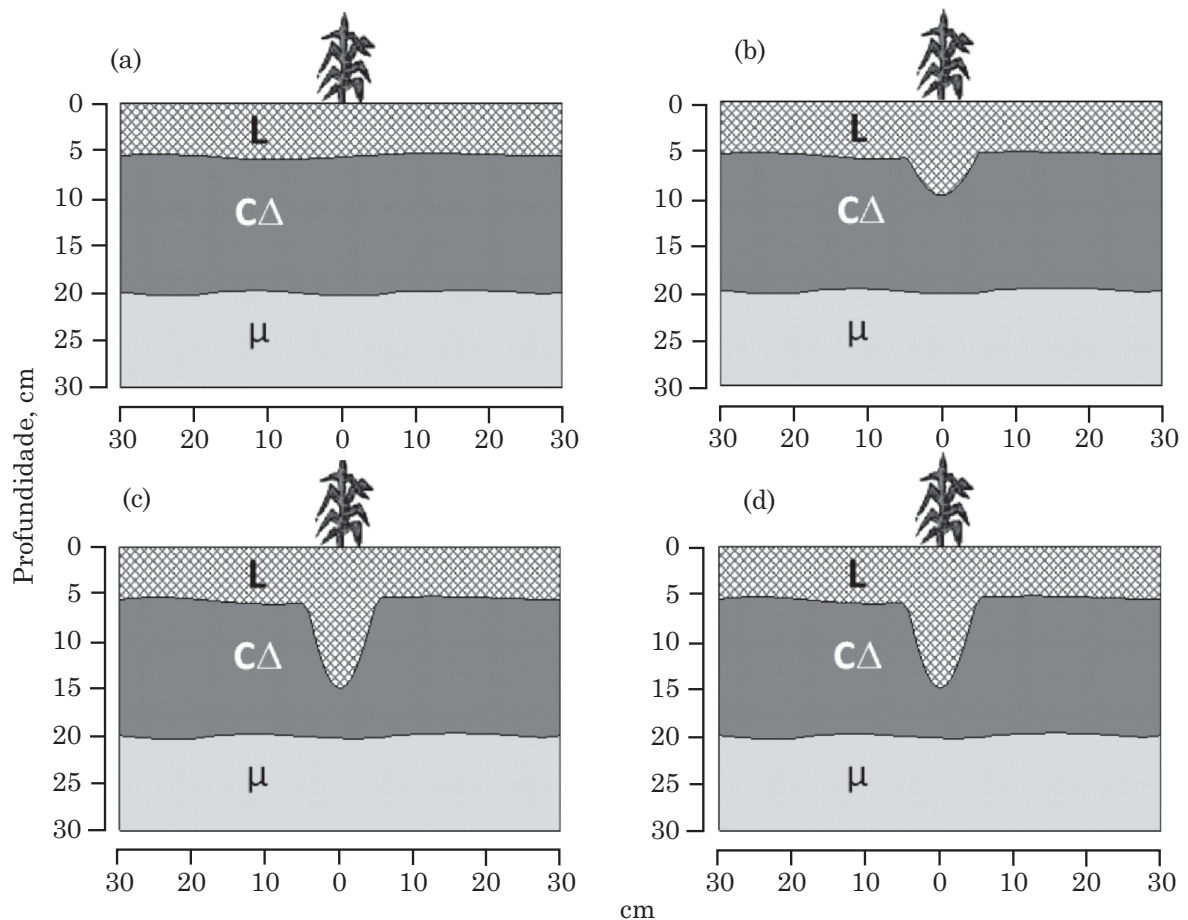

Figura 2. Perfil cultural do Latossolo Vermelho distrófico húmico, aos oito meses após a semeadura de milho (Zea mays L.), com semeadora equipada com haste sulcadora ajustada para operar a 5 (a), 10 (b), 15 (c) e $17 \mathrm{~cm}$ (d) de profundidade. L é a camada de solo solto com macro e microagregados, porosidade visível a olho nu e abundante presença de raízes; $\mathrm{C} \Delta$, a camada de solo com estrutura maciça e homogênea, sem porosidade visível a olho nu e menor presença de raízes em relação à camada $L ; \mathrm{e} \mu$, a camada de solo com estrutura na forma de grânulos e de blocos, típica de Latossolo Vermelho.

\section{RESULTADOS E DISCUSSÃO}

\section{Análise do perfil cultural e atributos físicos do solo}

O solo manejado sob "plantio direto" apresentou estratificação física na camada de $0-30 \mathrm{~cm}$, permitindo a identificação de três camadas distintas conforme método do perfil cultural (Figura 2). A análise quantitativa dos atributos físicos em cada camada (Quadro 2) corroboram essa análise qualitativa, evidenciando similaridade com aqueles obtidos por Drescher et al. (2011), também avaliados na região subtropical úmida do Brasil.

A camada L, similarmente à condição observada antes da implantação do ensaio, foi caracterizada por apresentar grande volume de solo solto e de estrutura granular, resultante da ação da haste sulcadora, e presença de elevada quantidade de raízes e de poros visíveis a olho nu. Os dados quantitativos, Ds $=1,04 \mathrm{~kg} \mathrm{dm}^{-3}, \mathrm{Ma}=0,19 \mathrm{~m}^{3} \mathrm{~m}^{-3}, \mathrm{Pt}=0,59 \mathrm{~m}^{3} \mathrm{~m}^{-3}$ e $\mathrm{RP}=64 \mathrm{kPa}$ (Quadro 2), obtidos nessa camada, evidenciaram condições físicas favoráveis ao desenvolvimento radicular das plantas. A espessura dessa camada, na linha de semeadura, variou de acordo com os tratamentos, sendo de $0-5 \mathrm{~cm}$, no $\mathrm{T}_{1 ;}$ de $0-10 \mathrm{~cm}$, no $\mathrm{T}_{2}$ : de $0-15 \mathrm{~cm}$, no $\mathrm{T}_{3}$; e de $0-17 \mathrm{~cm}$, no $\mathrm{T}_{4}$ (Figura 2), indicando a eficácia da ação da haste sulcadora.
A camada $\mathrm{C} \Delta$ foi caracterizada por apresentar volume de solo com agregados e terra fina unidos formando estrutura maciça e homogênea e agregados compactos, sem porosidade visível a olho nu e com menor concentração de raízes em relação à camada L. Os dados quantitativos, Ds $=1,39 \mathrm{~kg} \mathrm{dm}^{-3}, \mathrm{Ma}=0,07 \mathrm{~m}^{3} \mathrm{~m}^{-3}$, $\mathrm{Pt}=0,48 \mathrm{~m}^{3} \mathrm{~m}^{-3} \mathrm{eRP}=269 \mathrm{kPa}$ (Quadro 2) indicaram degradação estrutural do solo, com nítida restrição ao aprofundamento do sistema radicular da cultura de milho, com a espessura, na linha de semeadura, variando em razão do tratamento (Figura 2).

A camada $\mu$, não influenciada pelos tratamentos (Figura 2), foi caracterizada por aparência de solo não compactado, com estrutura na forma de grânulos e de blocos, típica desse Latossolo Vermelho. Os dados quantitativos, Ds $=1,28 \mathrm{~kg} \mathrm{dm}^{-3}, \mathrm{Ma}=0,09 \mathrm{~m}^{3} \mathrm{~m}^{-3}$, $\mathrm{Pt}=0,52 \mathrm{~m}^{3} \mathrm{~m}^{-3} \mathrm{eRP}=176 \mathrm{kPa}$ (Quadro 2) evidenciaram a ausência de compactação do solo.

Uma das razões da compactação não se manifestar na camada superficial do solo são as recorrentes mobilizações superficiais desse a cada safra, em razão da prática de semeadura de culturas de verão e inverno. O cultivo de cereais de inverno, em fileiras espaçadas de $17 \mathrm{~cm}$, mobiliza cerca de $30 \%$ do solo na camada de 0-5 cm de profundidade (Genro Junior et al., 2004). Isso, somado às mobilizações realizadas na semeadura das culturas de verão, pode ter contribuído para a 
Quadro 2. Densidade do solo (Ds), macroporosidade $(\mathrm{Ma})$, porosidade total $(\mathrm{Pt})$ e resistência do solo à penetração $(\mathrm{RP})$ das camadas estratificadas pelo perfil cultural de um Latossolo Vermelho distrófico húmico

\begin{tabular}{cccrc}
\hline Camada $^{(1)}$ & Ds & Ma & Pt & RP \\
\hline & $\mathrm{kg} \mathrm{dm}^{-3}$ & \multicolumn{2}{c}{$\mathrm{m}^{3} \mathrm{~m}^{-3}$} & \\
\cline { 3 - 4 } & $1,04 \mathrm{c}$ & $0,19 \mathrm{a}$ & $0,59 \mathrm{a}$ & $64 \mathrm{c}$ \\
$\mathrm{L}$ & $1,39 \mathrm{a}$ & $0,07 \mathrm{~b}$ & $0,48 \mathrm{c}$ & $269 \mathrm{a}$ \\
$\mathrm{C} \Delta$ & $1,21 \mathrm{~b}$ & $0,09 \mathrm{~b}$ & $0,52 \mathrm{~b}$ & $176 \mathrm{~b}$ \\
$\mu$ &
\end{tabular}

(1) Camada estratificada pelo perfil cultural, em que: L é a camada de solo solto com macro e microagregados, porosidade visível a olho nu e abundante presença de raízes; $\mathrm{C} \Delta$, a camada de solo com estrutura maciça e homogênea, sem porosidade visível a olho nu e menor presença de raízes em relação à camada L; e $\mu$, a camada de solo com estrutura na forma de grânulos e de blocos, típica de Latossolo. Médias seguidas por letras iguais, na coluna, não diferem entre si pelo teste de Tukey, a $5 \%$.

favorável condição estrutural do solo observada na camada L (Figura 2).

A haste sulcadora ajustada para operar até $5 \mathrm{~cm}$ de profundidade $\left(\mathrm{T}_{1}\right)$, no entanto, não adicionou condições físicas favoráveis ao desenvolvimento radicular do milho, além das que o solo já apresentava (Figura 2a), com valores médios de Ds, Ma, Pt e RP, oito meses após a semeadura, correspondendo a 1,09

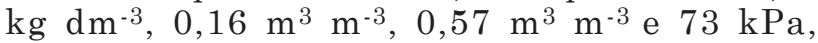
respectivamente (Quadro 3). Em contrapartida, a camada $\mathrm{C} \Delta(5-20 \mathrm{~cm})$ não foi mobilizada pela haste sulcadora da semeadora, permanecendo compactada e limitante ao desenvolvimento radicular das plantas, principalmente pelos maiores valores de Ds $(1,39 \mathrm{~kg}$ $\left.\mathrm{dm}^{-3}\right)$ e deficiente porosidade de aeração $\left(0,07 \mathrm{~m}^{3} \mathrm{~m}^{-3}\right)$ (Quadro 3). Beutler \& Centuriun (2004) observaram, em um Latossolo Vermelho, maior densidade e superfície radicular de soja na camada de $0-5 \mathrm{~cm}$, o que atribuíram à compactação da camada de $5-15 \mathrm{~cm}$. Para Camargo \& Alleoni (2006), a redução do tamanho dos poros, a ponto de impedir a passagem da raiz principal, leva a planta a expandir as raízes laterais com diâmetros menores, ocasionando concentração de raízes na camada superficial, o que predispõe a planta ao estresse hídrico, quando da ocorrência de estiagens.

Na camada L, entre os tratamentos, não houve diferença significativa (até $5 \%$ ) para as variáveis Ds, Ma, Pt e RP (Quadro 3). Assim, confirmou-se o dado qualitativo (Figura 2), apresentando que a maior profundidade de ação da haste sulcadora estendeu as condições físicas da camada L até as respectivas profundidades de ação das hastes sulcadoras, aumentando o volume de solo fisicamente favorável ao desenvolvimento radicular das plantas, corroborando os dados gerados por Cepik et al. (2010). Drescher et al. (2011) verificaram que a semeadora/adubadora, equipada com elemento rompedor de solo tipo disco de corte associado à haste sulcadora, eleva a Ma e reduz a
Ds, na camada de 7-15 cm, em comparação à semeadora/ adubadora equipada apenas com discos duplos.

Concomitante ao aumento da espessura da camada $\mathrm{L}$, houve redução da espessura da camada $\mathrm{C} \Delta$ (compactada), que foi rompida pela haste sulcadora, proporcionando, na linha de semeadura (Figura 2), efeito similar ao da escarificação tradicional do solo. Conforme observado por Drescher et al. (2011), a escarificação do solo promoveu melhorias físicas na camada compactada em solo manejado sob "plantio direto". Porém, Girardello et al. (2011) e Silva et al. (2012) observaram que o efeito da escarificação pode ser anulado em tempo inferior a um ano após a operação em um Latossolo Vermelho. Secco \& Reinert (1997) relataram que o efeito dessa prática persiste por apenas 10 meses em solo de textura muito argilosa.

A efemeridade dos efeitos da escarificação do solo pode estar vinculada à ação puramente mecânica dessa prática. Neste estudo, mesmo ocorrendo precipitações pluviais acima das normais para a região durante a condução do ensaio, o efeito positivo proporcionado pela ação da haste sulcadora de ação profunda $\left(\mathrm{T}_{4}\right)$ permaneceu no solo por pelo menos 12 meses. Os valores de Ds, Ma, Pt e RP, obtidos para $\mathrm{T}_{2}, \mathrm{~T}_{3}$ e $\mathrm{T}_{4}, 12$ meses após a operação, permaneceram similares àqueles obtidos no $\mathrm{T}_{1}$ (Quadro 3 ), indicando que as condições físicas favoráveis da camada superficial do solo $(0-5 \mathrm{~cm})$ são semelhantes àquelas obtidas a 10, 15 e $17 \mathrm{~cm}$ de profundidade, nos tratamentos $\mathrm{T}_{2}, \mathrm{~T}_{3}$ e $\mathrm{T}_{4}$, respectivamente.

O resultado da análise de interação época de amostragem vs tratamento (Quadro 3) não foi significativo (até $5 \%$ ) para as variáveis Ds e Pt e significativo para a RP e Ma. No $\mathrm{T}_{4}$, o contraste ortogonal indicou que a partir da primeira época de amostragem, aos oito meses, até a segunda, aos 12 meses, não houve diferença significativa nos valores de RP (Quadro 3). Esses resultados indicaram que não houve incremento nos valores de Ds e RP e tampouco diminuição da Pt do solo após a primeira coleta, realizada aos oito meses após a semeadura, até a segunda coleta, feita aos 12 meses após a semeadura do milho. Em relação à Ma, embora o contraste ortogonal tenha sido significativo (Quadro 3), os valores absolutos de Ma evidenciaram pequeno decréscimo, passando de 0,18 para $0,16 \mathrm{~m}^{3} \mathrm{~m}^{-3}$ (Quadro 3).

A persistência do efeito proporcionado pela haste sulcadora de ação profunda $\left(17 \mathrm{~cm}-\mathrm{T}_{4}\right)$, por mais de 12 meses, pode estar relacionado ao sistema radicular do milho, uma vez que esse teve desenvolvimento favorecido na área mobilizada pela haste sulcadora. Nicoloso et al. (2008) observaram que o efeito da escarificação em Latossolo de textura muito argilosa não perdurou por mais de nove meses. Porém, quando plantas de cobertura [aveia-preta e nabo-forrageiro (Raphanus sativus) + aveia-preta] foram introduzidas após a escarificação, o efeito foi mais prolongado, sendo atribuído, pelos autores, à presença de raízes no solo escarificado. 


\section{Atributos químicos do solo}

Na figura 3, são apresentadas as concentrações de $\mathrm{P}$ (a) e K (b) disponíveis, Ca (c) e Mg (d) trováveis nas camadas de solo estratificadas, na linha de semeadura, oito meses após a aplicação dos tratamentos; onde a mobilização de solo pela haste sulcadora limitou-se a 5 e $10 \mathrm{~cm}$ de profundidade, respectivamente $\mathrm{T}_{1} \mathrm{eT}_{2}$, a estratificação química no perfil do solo é acentuada, principalmente para os elementos $\mathrm{P}$ e K. Até $5 \mathrm{~cm}$ de profundidade, são observadas concentrações próximas a 70 e $500 \mathrm{mg} \mathrm{dm}^{-3}$ de $\mathrm{P}$ e K, respectivamente. A partir dos $7,5 \mathrm{~cm}$, as concentrações diminuem progressivamente atingindo 2 e $100 \mathrm{mg} \mathrm{dm}^{-3}$ de $\mathrm{Pe}$ $\mathrm{K}$, respectivamente, na camada de $20-22,5 \mathrm{~cm}$.

Maiores concentrações de nutrientes na camada superficial do solo em áreas sob "plantio direto", com ênfase para $\mathrm{P}$ e $\mathrm{K}$, são relatadas com frequência (Rheinheimer \& Anghinoni, 2001; Spera et al., 2011). Em "plantio direto", a aplicação de fertilizantes é realizada em superfície, e predominantemente no sulco de semeadura, safra após safra. Isto, somado à mineralização da matéria orgânica e à baixa mobilidade do P (Costa et al., 2009), proporcionam as maiores concentrações na camada superficial do solo.

Quadro 3. Densidade, macroporosidade, porosidade total e resistência à penetração do Latossolo Vermelho distrófico húmico, nas camadas estratificadas pelo perfil cultural, aos oito e 12 meses após a semeadura do milho (Zea mays $\mathrm{L}$.) com semeadora equipada com haste sulcadora ajustada para operar a $5\left(\mathrm{~T}_{1}\right), 10$ $\left(\mathrm{T}_{2}\right), 15\left(\mathrm{~T}_{3}\right)$ e $17 \mathrm{~cm}\left(\mathrm{~T}_{4}\right)$ de profundidade e significância para contraste de épocas e da interação épocas $\times$ profundidades da ação da haste

\begin{tabular}{|c|c|c|c|c|c|c|}
\hline \multirow{3}{*}{ Profundidade de ação da haste sulcadora } & \multicolumn{6}{|c|}{ Época/Camada ${ }^{(1)}$} \\
\hline & \multicolumn{3}{|c|}{ Oito meses } & \multicolumn{3}{|c|}{12 meses } \\
\hline & $\mathbf{L}$ & $\mathrm{C} \Delta$ & $\mu$ & $\mathbf{L}$ & $\mathbf{C} \Delta$ & $\mu$ \\
\hline \multicolumn{7}{|l|}{$\mathrm{cm}$} \\
\hline & \multicolumn{6}{|c|}{ Densidade do solo $\left(\mathrm{kg} \mathrm{dm}^{-3}\right)$} \\
\hline $\mathrm{T} 1=0-5$ & $1,09 \mathrm{c}$ & $1,39 \mathrm{a}$ & $1,22 \mathrm{~b}$ & $1,11 \mathrm{c}$ & $1,39 \mathrm{a}$ & $1,24 \mathrm{~b}$ \\
\hline $\mathrm{T} 2=0-10$ & $1,01 \mathrm{c}$ & $1,38 \mathrm{a}$ & $1,22 \mathrm{~b}$ & $1,16 \mathrm{~b}$ & $1,40 \mathrm{a}$ & $1,21 \mathrm{~b}$ \\
\hline $\mathrm{T} 3=0-15$ & $1,01 \mathrm{c}$ & $1,38 \mathrm{a}$ & $1,19 \mathrm{~b}$ & $1,14 \mathrm{~b}$ & $1,40 \mathrm{a}$ & $1,21 \mathrm{~b}$ \\
\hline $\mathrm{T} 4=0-17$ & $1,06 \mathrm{c}$ & $1,39 \mathrm{a}$ & $1,22 \mathrm{~b}$ & $1,15 \mathrm{c}$ & $1,39 \mathrm{a}$ & $1,21 \mathrm{~b}$ \\
\hline Oito vs 12 meses & & $\mathrm{ns}$ & & & & \\
\hline \multirow[t]{2}{*}{ Interação época $\times$ profundidade da haste } & \multirow{2}{*}{\multicolumn{6}{|c|}{ Macroporosidade $\left(\mathrm{m}^{3} \mathrm{~m}^{-3}\right)$}} \\
\hline & & & & & & \\
\hline $\mathrm{T} 1=0-5$ & 0,16 a & $0,07 \mathrm{~b}$ & $0,09 \mathrm{~b}$ & $0,16 \mathrm{a}$ & $0,07 \mathrm{~b}$ & $0,08 \mathrm{~b}$ \\
\hline $\mathrm{T} 2=0-10$ & $0,21 \mathrm{a}$ & $0,07 \mathrm{~b}$ & $0,08 \mathrm{~b}$ & $0,14 \mathrm{a}$ & $0,07 \mathrm{~b}$ & $0,09 \mathrm{~b}$ \\
\hline $\mathrm{T} 3=0-15$ & $0,21 \mathrm{a}$ & $0,08 \mathrm{~b}$ & $0,10 \mathrm{~b}$ & $0,16 \mathrm{a}$ & $0,06 \mathrm{~b}$ & $0,07 \mathrm{~b}$ \\
\hline $\mathrm{T} 4=0-17$ & $0,18 \mathrm{a}$ & $0,07 \mathrm{~b}$ & $0,07 \mathrm{~b}$ & $0,16 \mathrm{a}$ & $0,07 \mathrm{~b}$ & $0,07 \mathrm{~b}$ \\
\hline Oito vs 12 meses & & * & & & & \\
\hline \multirow[t]{2}{*}{ Interação época $\times$ profundidade da haste } & & * & & & & \\
\hline & \multicolumn{6}{|c|}{ Porosidade total $\left(\mathrm{m}^{3} \mathrm{~m}^{-3}\right)$} \\
\hline $\mathrm{T} 1=0-5$ & $0,57 \mathrm{a}$ & $0,47 \mathrm{c}$ & $0,52 \mathrm{~b}$ & $0,57 \mathrm{a}$ & $0,44 \mathrm{~b}$ & $0,58 \mathrm{~b}$ \\
\hline $\mathrm{T} 2=0-10$ & $0,61 \mathrm{a}$ & $0,48 \mathrm{~b}$ & $0,51 \mathrm{~b}$ & $0,55 \mathrm{a}$ & $0,48 \mathrm{a}$ & $0,49 \mathrm{a}$ \\
\hline $\mathrm{T} 3=0-15$ & $0,61 \mathrm{a}$ & $0,49 \mathrm{~b}$ & $0,53 \mathrm{~b}$ & $0,56 \mathrm{a}$ & $0,50 \mathrm{~b}$ & $0,54 a b$ \\
\hline $\mathrm{T} 4=0-17$ & $0,56 \mathrm{a}$ & $0,46 \mathrm{c}$ & $0,51 \mathrm{~b}$ & $0,53 \mathrm{a}$ & $0,49 \mathrm{~b}$ & $0,50 \mathrm{ab}$ \\
\hline Oito vs 12 meses & & $\mathrm{ns}$ & & & & \\
\hline \multirow[t]{2}{*}{ Interação época $\times$ profundidade da haste } & & $\mathrm{ns}$ & & & & \\
\hline & \multicolumn{6}{|c|}{ Resistência do solo à penetração (kPa) } \\
\hline $\mathrm{T} 1=0-5$ & $73 \mathrm{c}$ & $271 \mathrm{a}$ & $167 \mathrm{~b}$ & $110 \mathrm{~b}$ & $282 \mathrm{a}$ & $162 \mathrm{~b}$ \\
\hline $\mathrm{T} 2=0-10$ & $52 \mathrm{c}$ & $244 \mathrm{a}$ & $173 \mathrm{~b}$ & $123 \mathrm{~b}$ & 269 a & $173 \mathrm{~b}$ \\
\hline $\mathrm{T} 3=0-15$ & $56 \mathrm{c}$ & $265 \mathrm{a}$ & $175 \mathrm{~b}$ & $121 \mathrm{~b}$ & $279 \mathrm{a}$ & $178 \mathrm{ab}$ \\
\hline $\mathrm{T} 4=0-17$ & $75 \mathrm{c}$ & $296 \mathrm{a}$ & $190 \mathrm{~b}$ & $107 \mathrm{~b}$ & $269 \mathrm{a}$ & $161 \mathrm{~b}$ \\
\hline Oito vs 12 meses & & * & & & & \\
\hline Interação época $\times$ profundidade da haste & & $\mathrm{ns}$ & & & & \\
\hline
\end{tabular}

(1) Camada estratificada pelo perfil cultural, em que: L é a camada de solo solto com macro e microagregados, porosidade visível a olho nu e abundante presença de raízes; $\mathrm{C} \Delta$, a camada de solo com estrutura maciça e homogênea, sem porosidade visível a olho nu e menor presença de raízes em relação à camada L; e $\mu$, a camada de solo com estrutura na forma de grânulos e de blocos, típica de Latossolo. Média seguida pela mesma letra, na linha e em cada época, não difere entre si pelo teste Tukey a 5 \%; ns não significativo. 
Selles et al. (1997) observaram maiores concentrações de $\mathrm{P}$ disponível em um Latossolo Vermelho sob "plantio direto" entre 0-6 cm de profundidade, com redução drástica na camada de 6$10 \mathrm{~cm}$. Esses autores relataram que, após cinco anos da adoção do "plantio direto", os teores de P na camada de $0-10 \mathrm{~cm}$ aumentaram $15 \%$ em relação ao solo conduzido com preparo convencional. Em um Latossolo Vermelho, inicialmente com teor de $\mathrm{P}$ muito baixo, após 14 anos sob "plantio direto" com aplicação de $80 \mathrm{~kg} \mathrm{ha}^{-1}$ ano $^{-1}$ de $\mathrm{P}_{2} \mathrm{O}_{5}$ no sulco de semeadura ou a lanço em superfície, Nunes et al. (2011) observaram forte gradiente, sendo os maiores teores de P encontrados na camada 0-2,5 cm do solo. Da mesma forma, Spera et al. (2011) verificaram na camada de 0-6,8 cm de um Latossolo Vermelho sob "plantio direto" elevada concentração de nutrientes, principalmente de P e K.

Apesar de a concentração do sistema radicular na camada superficial do solo sob "plantio direto" ser creditada, principalmente às condições físicas restritivas impostas pela camada de $5-20 \mathrm{~cm}$ do solo (Beutler \& Centurion, 2004; Secco et al., 2009;

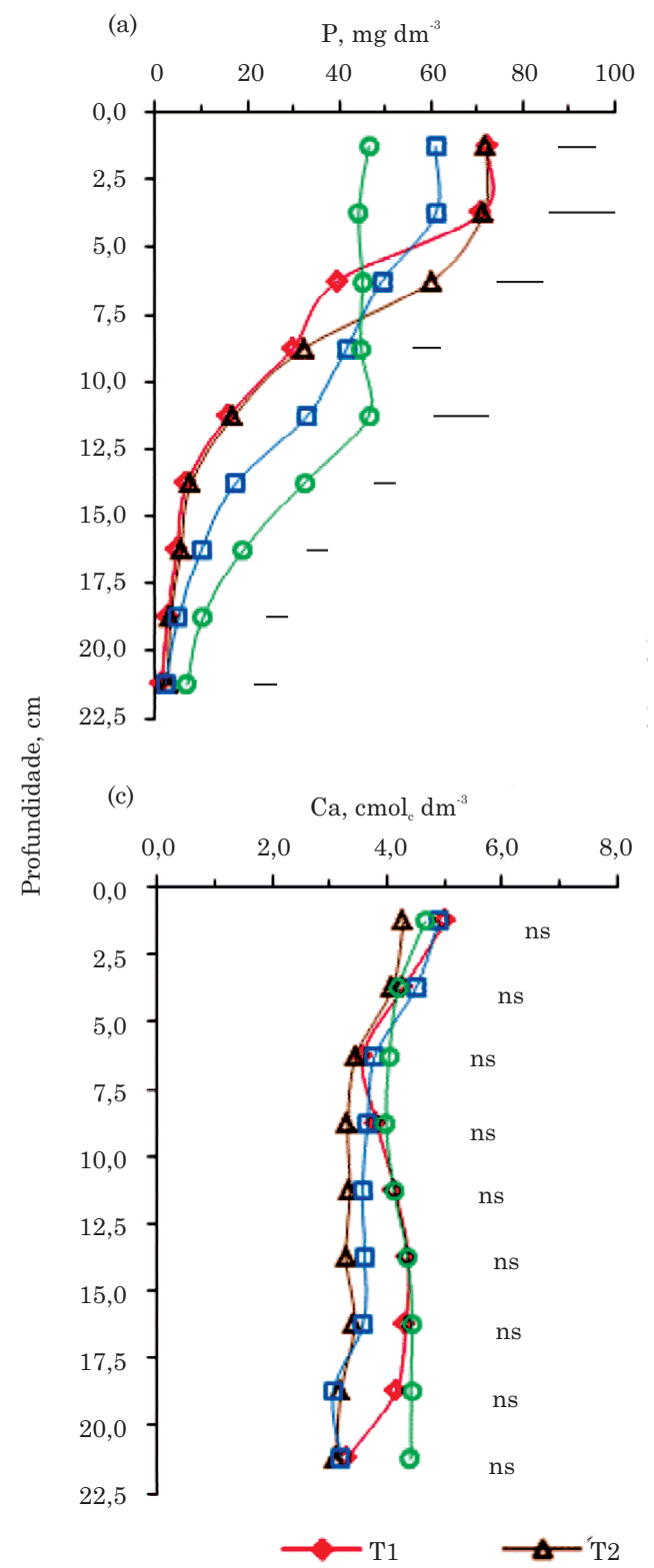

(b)

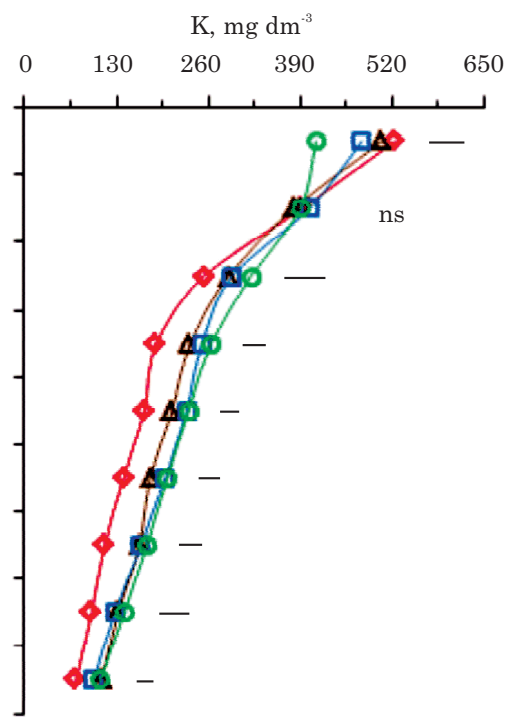

(d)

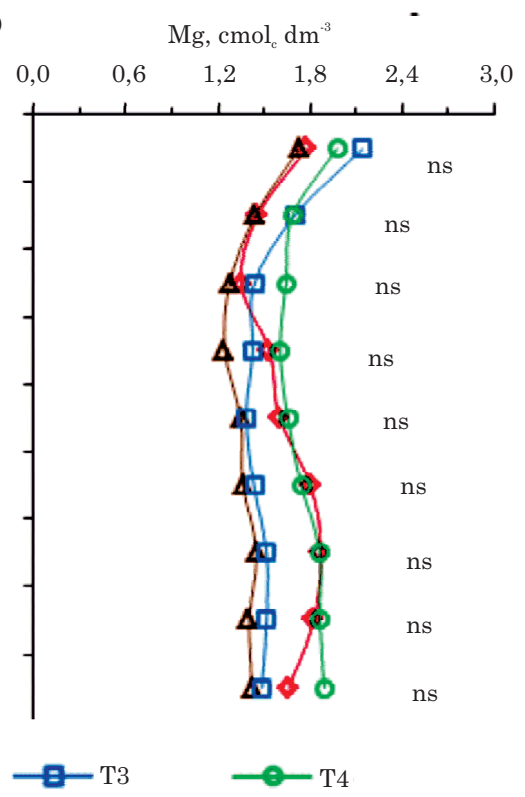

Figura 3. Concentrações de $\mathrm{P}$ (a) e K (b) disponíveis, Ca (c) e Mg (d) trocáveis, oito meses após a semeadura de milho (Zea mays L.), com semeadora equipada com haste sulcadora ajustada para operar a diferentes profundidades, em Latossolo Vermelho sob plantio direto, na linha de semeadura. $T_{1}$ : ação da haste sulcadora a $5 \mathrm{~cm} ; T_{2}$ : ação da haste sulcadora a $10 \mathrm{~cm}$; $T_{3}$ : ação da haste sulcadora a $1_{5} \mathrm{~cm}$; e $T_{4}$ : ação da haste sulcadora a $17 \mathrm{~cm}$; Barras horizontais representam a diferença mínima significativa pelo teste Tukey a $5 \%$, entre os tratamentos. 
Bergamin et al., 2010), a fertilidade desfavorável nessa camada também pode estar restringindo o aprofundamento das raízes (Spera et al., 2011). Nesse sentido, observa-se na figura 4 , para o tratamento $\mathrm{T}_{1}$, que na camada de 7,5-17,5 cm, fisicamente degradada, o solo apresenta-se mais ácido, com menor $\mathrm{pH}$ $\left(\mathrm{H}_{2} \mathrm{O}\right)$ (Figura 4a), maior concentração de $\mathrm{Al}$ trocável (Figura $4 \mathrm{~b}$ ), que ultrapassa a $1,5 \mathrm{cmol}_{\mathrm{c}} \mathrm{dm}^{-3}$, e elevada acidez potencial (Figura 4c). Esses dados fortalecem o alerta realizado por Denardin et al. (2008) para uma

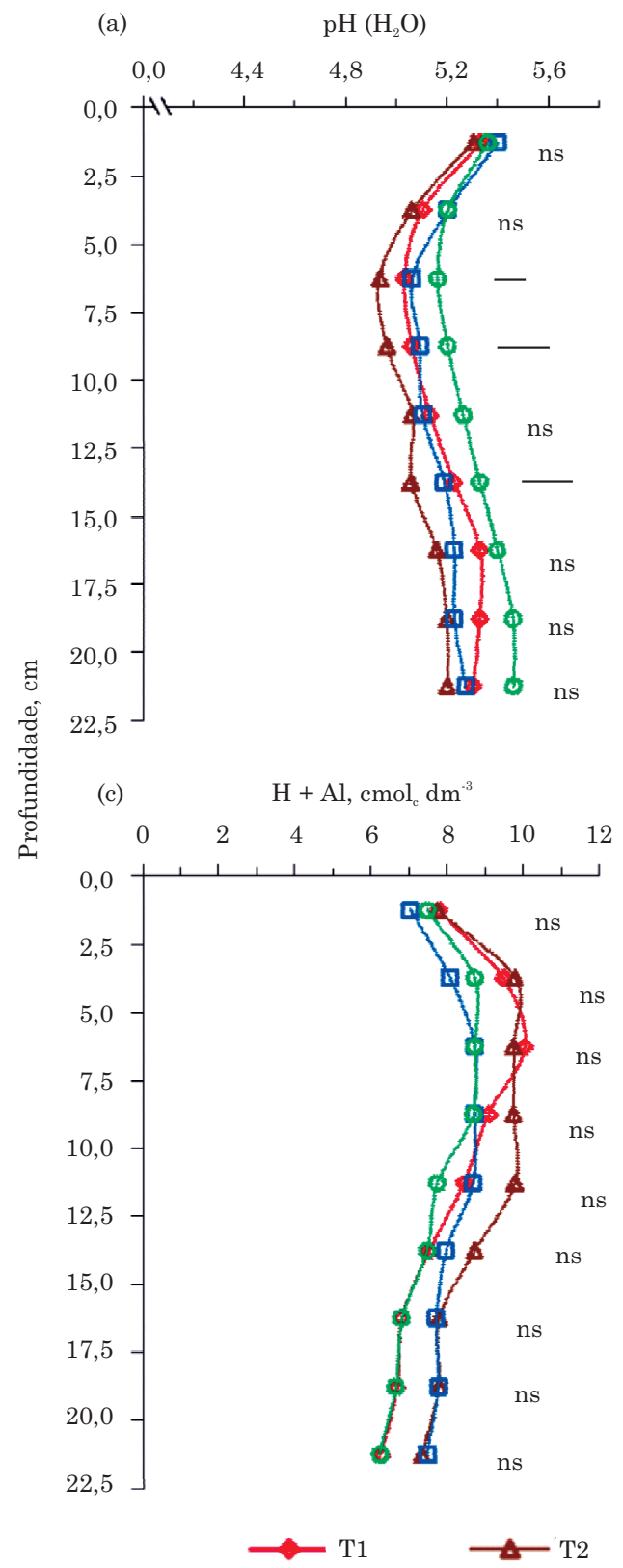

distribuição superficial de fertilizantes, quando da utilização de semeadora/adubadora equipada com elemento rompedor de solo que atua superficialmente, corroborando os dados de Spera et al. (2011). Esses autores discutiram que os atributos químicos de um Latossolo Vermelho manejado sob "plantio direto", na camada de 0-6,8 cm, são adequados para o desenvolvimento das culturas, porém, na camada de 6,8-20 cm, o nível de acidez pode estar restringindo o desenvolvimento radicular das plantas cultivadas. (b)
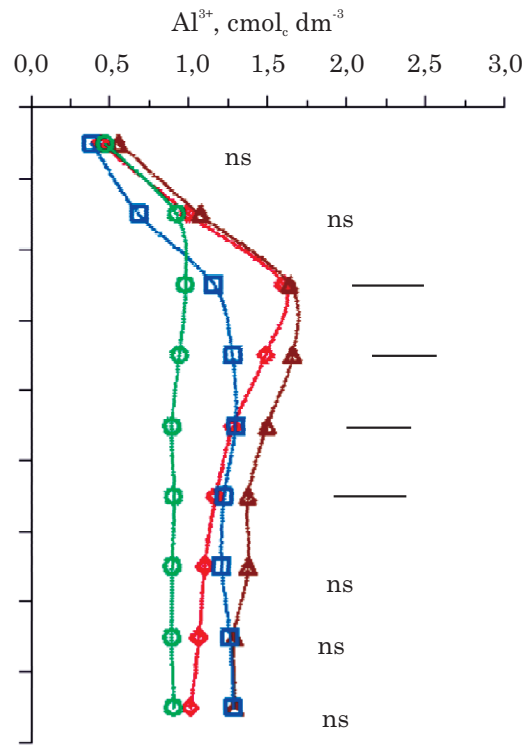

(d)

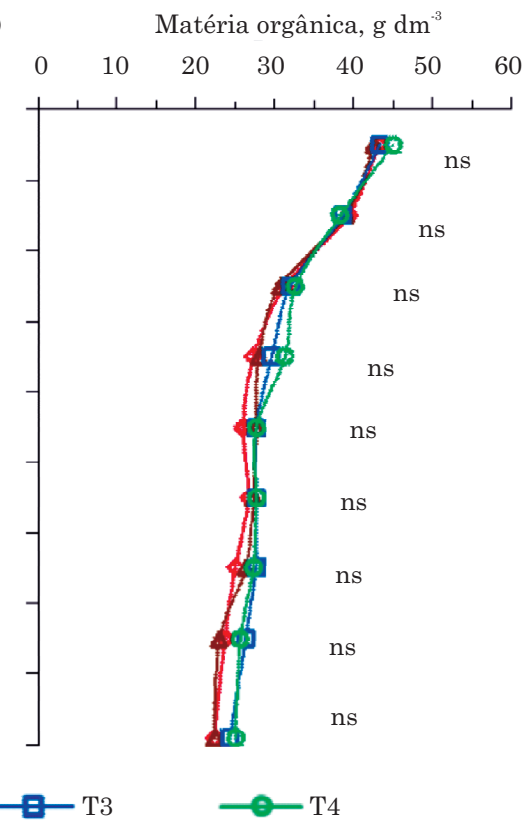

Figura 4. pH em água (a), alumínio trocável (b), acidez potencial (c) e matéria orgânica (d), oito meses após a semeadura do milho (Zea mays L.), com semeadora equipada com haste sulcadora ajustada para operar a diferentes profundidades, em Latossolo Vermelho sob plantio direto, obtidos na linha de semeadura. $T_{1}$ : ação da haste sulcadora a $5 \mathrm{~cm} ; T_{2}$ : ação da haste sulcadora a $10 \mathrm{~cm} ; T_{3}$ : ação da haste sulcadora a $1_{5} \mathrm{~cm}$; e $T_{4}$ : ação da haste sulcadora a $17 \mathrm{~cm}$; Barras horizontais representam a diferença mínima significativa pelo teste Tukey a $5 \%$, entre os tratamentos. 
Quando da utilização da semeadura equipada com haste sulcadora ajustada para operar a $17 \mathrm{~cm}$ de profundidade $\left(\mathrm{T}_{4}\right)$, as concentrações de $\mathrm{P}$ e $\mathrm{K}$ disponíveis na camada $0,0-2,5 \mathrm{~cm}$ diminuíram significativamente em relação às concentrações desses elementos em $\mathrm{T}_{1}$ e $\mathrm{T}_{2}$, onde a haste sulcadora atuou a 5 e $10 \mathrm{~cm}$ de profundidade, respectivamente. Salientase que, embora essas concentrações tenham diminuído na camada superficial, esses elementos continuam em teores suficientes para suprir a necessidade das plantas (próximos a 40 e $400 \mathrm{mg} \mathrm{dm}^{-3}$ de $\mathrm{P}$ e K, respectivamente) (Figura 3). Na camada $2,5-5,0 \mathrm{~cm}$, a diminuição do $\mathrm{P}$ também foi significativa, o que não ocorreu para o $\mathrm{K}$, provavelmente por causa da facilidade com que esse elemento é lixiviado no solo, uma vez que a coleta nele foi realizada oito meses após a deposição do fertilizante.

Abaixo dos $5 \mathrm{~cm}$ de profundidade, as concentrações de $\mathrm{K}$ aumentaram significativamente quando da utilização da haste sulcadora atuando a $17 \mathrm{~cm}\left(\mathrm{~T}_{4}\right)$. Esse aumento também foi observado para as concentrações de $\mathrm{P}$, porém abaixo dos $7,5 \mathrm{~cm}$ (Figura 3 ). A partir dessa profundidade até a camada mais profunda avaliada $(20,0-22,5 \mathrm{~cm})$, as concentrações, tanto de $\mathrm{P}$ quando de $\mathrm{K}$, foram tanto maiores quanto maior a profundidade de ação do elemento rompedor de solo utilizado na semeadora/adubadora. Assim, quanto maior a profundidade de ação da haste sulcadora da semeadora/adubadora, utilizada para a semeadura do milho, menor foi a estratificação desses elementos na camada superficial $(0,0-22,5 \mathrm{~cm})$ do solo em "plantio direto".

A evidente diminuição do grau de estratificação dos teores desses nutrientes decorre da deposição do adubo em maior profundidade proporcionada pela ação da haste sulcadora. Essa pode ter facilitado a movimentação dos nutrientes, já que houve aumento significativo da macroporosidade (Quadro 3) e, portanto, maior permeabilidade do solo à água. Dessa forma, parte do fertilizante pode ter se deslocado para camadas mais profundas, aumentando os níveis na camada compactada $(5-20 \mathrm{~cm})$.

Em relação à acidez do solo, na camada compactada $(5-20 \mathrm{~cm})$, há tendência de diminuição do $\mathrm{pH}$ e aumento do teor de $\mathrm{Al}^{3+}$ e da acidez potencial (Figura 4), com valores, respectivamente, maiores e menores de $\mathrm{pH}$ e $\mathrm{Al}^{3+}$ no $\mathrm{T}_{4}$. $\mathrm{O}$ observado pode estar relacionado às calagens realizadas exclusivamente em superfície no "plantio direto" há mais de 10 anos, e provável incorporação desse quando da utilização da haste sulcadora de ação profunda $(17 \mathrm{~cm})\left(\mathrm{T}_{4}\right)$. Azevedo et al. (1996) detectaram efeito da calagem sobre $\mathrm{pH}$ e teores de $\mathrm{Al}^{3+} 23$ anos depois da aplicação de calcário em um Latossolo Bruno. Kaminski et al. (2005) observaram a persistência do efeito da calagem por um período superior a sete anos em um Argissolo sob plantio direto.

Dessa forma, a melhora nos atributos químicos do solo em profundidade pode contribuir para o aprofundamento das raízes das culturas, tanto da safra de verão quanto da de inverno. Isso é altamente desejado, pois, em longo prazo, pode contribuir também para a melhoria do estado de agregação do solo da camada degradada $(5-20 \mathrm{~cm})$ por meio da incorporação de carbono orgânico, via sistema radicular, contribuindo para a reestruturação do mesmo (Salton et al., 2008; Garcia \& Rosolem, 2010).

\section{CONCLUSÕES}

1. O emprego da semeadora/adubadora equipada com haste sulcadora, para a semeadura de milho em área manejada sob "plantio direto", proporcionou aumento da macroporosidade e da porosidade total do solo e redução da densidade e resistência do solo à penetração da camada compactada na linha de semeadura, bem como diminuição da estratificação química no perfil do solo, principalmente de $\mathrm{Pe} \mathrm{K}$.

2. O emprego da semeadora/adubadora equipada com haste sulcadora ajustada para operar a $17 \mathrm{~cm}$ de profundidade foi mais eficiente em mitigar os problemas de ordem física e química do solo em "plantio direto".

3. A melhoria da qualidade física do solo da camada subsuperficial, proporcionada pela utilização de semeadora/adubadora equipada com haste sulcadora de ação profunda $(17 \mathrm{~cm})$ para semeadura de milho em "plantio direto" persistiu por pelo menos 12 meses no solo.

\section{LITERATURA CITADA}

AZEVEDO, A.C.; KÄMPF, N. \& BOHNEN, H. Alterações na dinâmica evolutiva de Latossolo Bruno pela calagem. R. Bras. Ci. Solo, 20:191-198, 1996.

BERGAMIN, A.C.; VITORINO, A.C.T.; FRANCHINI, J.C.; SOUZA, C.M.A. \& SOUZA, F.R. Compactação em um Latossolo Vermelho distroférrico e suas relações com o crescimento radicular do milho. R. Bras. Ci. Solo, 34:681-691, 2010.

BEUTlER, A.N. \& CENTURION, J.F. Compactação do solo no desenvolvimento radicular e na produtividade de soja. Pesq. Agropec. Bras., 39:581-588, 2004.

CAMARGO, O.A. \& ALLEONI, L.R.F. Efeitos da compactação em atributos do solo, 2006. Disponível em: <http://www.infobibos.com/Artigos/CompSolo/C4/ Comp4.htm>. Acesso em: 12 jun. 2012.

CEPIK, C.T.C.; TREIN, C.R.; LEVIEN, R. \& CONTE, O. Força de tração e mobilização do solo por hastes sulcadoras de semadoras-adubadoras. R. Bras. Eng. Agríc. Amb., 14:561-566, 2010. 
CHEN, G. \& WEIL, R.R. Root growth and yield of maize as affected by soil compaction and cover crops. Soil Till. Res., 117:17-27, 2011.

COSTA, S.E.V.G.A.; SOUZA, E.D.; ANGHINONI, I.; FLORES, J.P.C.; C.A.O, E.G. \& HOLZSCHUH, M.J. Phosphorus and root distribution and corn growth as related to longterm tillage systems and fertilizer placement. R. Bras. Ci. Solo, 33:1237-1247, 2009.

DE MARIA, I.C.; CASTRO, O.M. \& DIAS, H.S. Atributos físicos do solo e crescimento radicular de soja em Latossolo Roxo sob diferentes métodos de preparo do solo. R. Bras. Ci. Solo, 23:703-709, 1999.

DENARDIN, J.E.; KOCHHANN, R.A. \& FAGANELLO, A. 15 de abril dia nacional da conservação do solo: A agricultura desenvolvida no Brasil é conservacionista ou não? B. Inf. SBCS, 36:10-15, 2011.

DENARDIN, J.E.; KOCHHANN, R.A.; BACALTCHUK, B.; SATTLER, A.; DENARDIN, N.D'A.; FAGANELLO, A. \& WIETHÖLTER, S. Sistema plantio direto: Fator de potencialidade da agricultura tropical brasileira. In: ALBUQUERQUE, A.C.S. \& SILVA, A.G., eds. Agricultura tropical: Quatro décadas de inovações tecnológicas, institucionais e políticas. Brasília, Embrapa Informação Tecnológica, 2008. v.1, p.1251-1273.

DIAS JR, M.S. \& PIERCE, F.J. O processo de compactação do solo e sua modelagem. R. Bras. Ci. Solo, 20:175-182, 1996.

DRESCHER, M.S.; ELTZ, F.L.F.; DENARDIN, J.E. \& FAGANELLO, A. Persistência do efeito de intervenções mecânicas para a descompactação de solos sob plantio direto. R. Bras. Ci. Solo, 35:1713-1722, 2011.

EMPRESA BRASILEIRA DE PESQUISA AGROPECUÁRIA EMBRAPA. Centro Nacional de Pesquisa de Solos. Manual de métodos de análises de solo. 2.ed. Rio de Janeiro, 1997. 212p.

FREDDI, O.S.; CENTURION, J.F.; BEUTLER, M.N.; ARATANI, R.G.; LEONEL, C.L. \& SILVA, A.P. Compactação do solo e intervalo hídrico ótimo no crescimento e na produtividade da cultura do milho. R. Ci. Agron., 66:477486, 2007.

GARCIA, R.A. \& ROSOLEM, C.A. Agregados em um Latossolo sob sistema plantio direto e rotação de culturas. Pesq. Agropec. Bras., 45:1489-1498, 2010.

GENRO JUNIOR, S.A.; REINERT, D.J. \& REICHERT, J.M. Variabilidade temporal da resistência à penetração de um Latossolo argiloso sob semeadura direta com rotação de culturas. R. Bras. Ci. Solo, 28:477-484, 2004.

GIRARDELLO, V.C.; AMADO, T.J.C.; NICOLOSO, R.S.; HÖRBE, T.A.N.; FERREIRA, A.O.; TABALDI, F.M. \& LANZANOVA, M.E. Alterações nos atributos físicos de um Latossolo Vermelho sob plantio direto induzidas por diferentes tipos de escarificadores e o rendimento da soja. R. Bras. Ci. Solo, 35:2115-2126, 2011.

HAMZA, M.A. \& ANDERSON, W.K. Soil compaction in cropping systems. A review of the nature, causes and possible solutions. Soil Till. Res., 82:121-145, 2005.
KAMINSKI, J.; RHEINHEIMER, D.S.; GATIBONI, L.C.; BRUNETTO, G. \& SILVA, L.S. Eficiência da calagem superficial e incorporada precedendo o sistema plantio direto em um Argissolo sob pastagem natural. R. Bras. Ci. Solo, 29:573-580, 2005.

KLEIN, V.A.; VIEIRA, M.L.; DURIGON, F.F.; MASSING, J.P. \& FÁVERO, F. Porosidade de aeração de um Latossolo Vermelho e rendimento de trigo em plantio direto escarificado. Ci. Rural, 38:365-371, 2008.

LANZANOVA, M.E.; NICOLOSO, R.S.; LOVATO, T.; ELTZ, F.L.F.; AMADO, T.J.C. \& REINERT, D.J. Atributos físicos do solo em sistema de integração lavourapecuária sob plantio direto. R. Bras. Ci. Solo, 31:11311140, 2007.

NICOLOSO, R.S.; AMADO, T.J.C.; SCHNEIDER, S.; LANZANOVA, M.E.; GIRARDELLO, V.C. \& BRAGAGNOLO, J. Eficiência da escarificação mecânica e biológica na melhoria dos atributos físicos de um Latossolo muito argiloso e no incremento do rendimento de soja. R. Bras. Ci. Solo, 32:1723-1734, 2008.

NUNES, R.S.; SOUSA, D.M.G.; GOEDERT, W.J. \& VIVALDI, L.J. Distribuição de fósforo no solo em razão do sistema de cultivo e manejo da adubação fosfatada. R. Bras. Ci. Solo, 35:877-888, 2011.

REICHERT, J.M.; SUZUKI, L.E. \& REINERT, D.J. Compactação do solo em sistemas agropecuários e florestais: identificação, efeitos, limites críticos e mitigação. In: CERETTA, C.A.; SILVA, L.S. \& REICHERT, J.M., eds. Tópicos em ciência do solo. Viçosa, MG, Sociedade Brasileira de Ciência do Solo, 2007. v.4, p.49-134.

RHEINHEIMER, D.S. \& ANGHINONI, I. Distribuição do fósforo inorgânico em sistemas de manejo de solo. Pesq. Agropec. Bras., 36:151-160, 2001.

RICHART, A.; TAVARES FILHO, J.; RODRIGUES, B.O.; LLANILLO, R.F. \& FERREIRA, R. Compactação do solo: causas e efeitos. Semina: Ci. Agron., 26:321-344, 2005 .

SALTON, J.C.; MIELNICZUK, J.; BAYER, C.; BOENI, M.; CONCEIÇÃO, P.C.; FABRÍCIO, A.C.; MACEDO, M.C.M. \& BROCH, D.L. Agregação e estabilidade de agregados do solo em sistemas agropecuários em mato grosso do sul. R. Bras. Ci. Solo, 32:11-21, 2008.

SAS INSTITUTE. SAS/STAT procedure guide for personal computers. 5.ed. Cary, 2009.

SECCO, D. \& REINERT, D.J. Efeitos imediato e residual de escarificadores em Latossolo Vermelho-Escuro sob PD. Eng. Agríc., 16:52-61, 1997.

SECCO, D.; REINERT, D.J.; REICHERT, J.M. \& SILVA, V.R. Atributos físicos e rendimento de grãos de trigo, soja e milho em dois Latossolos compactados e escarificados. Ci. Rural, 39:58-64, 2009.

SELLES, F.; KOCHHANN, R.A.; DENARDIN, J.E.; ZENTER, R.P. \& FAGANELLO, A. Distribution of phosphorus fractions in a Brazilian Oxisol under different tillage systems. Soil Till. Res., 44:23-34, 1997. 
SILVA, S.G.C.; SILVA, A.P.; GIAROLA, N.F.B.; TORMENA, C.A. \& SÁ, J.C.M. Temporary effect of chiseling on the compaction of a Rhodic Hapludox under no-tillage. R. Bras. Ci. Solo, 36:547-555, 2012.

SILVA, V.R.; REICHERT, J.M.; REINERT, D.J. \& BORTOLUZZI, E.C. Soil water dynamics related to the degree of compaction of two Brazilian Oxisols under notillage. R. Bras. Ci. Solo, 23:35-43, 2009.

SILVEIRA, P.M.; STONE, L.F.; ALVES JÚNIOR J. \& SILVA, J.G. Efeitos do manejo do solo sob plantio direto e de culturas na densidade e porosidade de um Latossolo. Biosci. J., 24:53-59, 2008.

SPERA, S.T.; ESCOSTEGUY, P.A.V.; DENARDIN, J.E.; KLEIN, V.A. \& SANTOS, H.P. Atributos químicos restritivos de Latossolo Vermelho distrófico e tipos de manejo de solo e rotação de culturas. R. Agr., 4:324-334, 2011.

STONE, L.F. \& SILVEIRA, P.M. Efeitos do sistema de preparo e da rotação de culturas na porosidade e densidade do solo. R. Bras. Ci. Solo, 25:395-401, 2001.

STRECK, E.V.; KÄMPF, N.; DALMOLIN, R.S.D.; KLAMT, E.; NASCIMENTO, P.C.; SCHNEIDER, P.; GIASSON, E. \& PINTO L.F.S. Solos do Rio Grande do Sul. 2.ed. Porto Alegre, Emater/RS, 2008. 222p.
TAVARES FILHO, J.; RALISCH, R.; GUIMARÃES, M.F.; MEDINA, C.C.; BALBINO, L.C. \& NEVES, C.S.V.J. Método do perfil cultural para avaliação do estado físico de solos em condições tropicais. R. Bras. Ci. Solo, 23:39399, 1999.

TORMENA, C.A.; ROLOFF, G. \& SÁ, J.C.M. Propriedades físicas do solo sob plantio direto influenciado por calagem, preparo inicial e tráfego. R. Bras. Ci. Solo, 22:301-309, 1998.

TORMENA, C.A.; VIDIGAL FILHO, P.S.; GONÇALVES, A.C.A.; ARAÚJO, M.A. \& PINTRO, J.C. Influência de diferentes sistemas de preparo do solo nas propriedades físicas de um Latossolo Vermelho distrófico. R. Bras. Eng. Agríc. Amb., 8:65-71, 2004.

VEIGA, M.; HORN, R.; REINERT, D.J. \& REICHERT, J.M. Soil compressibility and penetrability of an Oxisol from southern Brazil, as affected by long-term tillage systems. Soil Till. Res., 92:104-113, 2007.

VEIGA, M.; REINERT, D.J.; REICHERT, J.M. \& KAISER, D.R. Short and long-term effects of tillage systems and nutrient sources on soil physical properties of a southern Brazilian Hapludox. R. Bras. Ci. Solo, 32:1437-1446, 2008.

VIEIRA, M.L. \& KLEIN, V.A. Propriedades físico-hídricas de um Latossolo Vermelho submetido a diferentes sistemas de manejo. R. Bras. Ci. Solo, 31:1271-1280, 2007. 